\title{
SİGORTACILIK SEKTÖRÜNÜN İŞ SAĞLIĞI VE GÜVENLİĞİNE BAKIŞ AÇISI: ERZURUM İLİ ÜZERINE BİR ARAŞTIRMA*
}

\author{
Yavuz KOTAN $^{1}$
}

Sigorta Uzmanı \& Bilim Uzmanı

E-mail: yavuzktn@gmail.com

ORCID ID: 0000-0002-9898-9755

\section{Özgür KOTAN}

Dr.

Atatürk Üniversitesi, Fen Bilimleri Enstitüsü

E-mail: ozgurkotan2525@gmail.com

ORCID ID: 0000-0002-4639-2797

$\ddot{O} z$

Bu çalışmada sigortacılık sektöründe iş sağlı̆̆l ve güvenliği ele alınmıştır. Sanayi ve ekonominin gelişmesi ile birlikte birçok sektörde çalışma koşulları değişmiş, bunun sonucu olarak işyerlerinde yaşanan olumsuz olaylar ve iş kazalarında artış yaşanmıştır. Sigortacılık sektöründeki şirketler bu olumsuz olayların önüne geçebilmek için bazı tedbirler almıştır. Bu tedbirlerin başında ise iş sağlı̆̆ ve güvenliği ile ilgili faaliyetler gelmektedir. Böylece sigorta şirketleri, çalışanlarına

* Bu çalışmada bilimsel araştırma ve yayın etiği ilkelerine uyulmuştur.

Bu çalışma için Atatürk Üniversitesi'nin 28.04.2021 tarihli ve E-77040475-000-2100129126 sayılı Üniversite Etik Kurulu Kararı ile etik kurul onayı alınmıştır.

${ }^{1}$ Sorumlu Yazar: yavuzktn@gmail.com

Atıf (APA): Kotan, Y. \& Kotan, Ö., (2021), Sigortacılık Sektörünün İş Sağlığı ve Güvenliğine Bakış Açısı: Erzurum İli Üzerine Bir Araştırma, Hukuk ve İktisat Araştırmaları Dergisi, 13 (2): 138-150., https://doi.org/10.53881/hiad.899275

Lisans: Bu makalenin kullanım izni Creative Commons Attribution-NoCommercial-NoDerivs 3.0 Unported (CC BY-NC-ND3.0) lisansı aracılığıyla bedelsiz sunulmaktadır. 
sağllklı ve güvenli bir ortamda çalışma firsatı sunmak için iş sağlı̆̆g ve güvenliği kavramından faydalanarak bu durumu benimsetmeye çalışmaktadırlar. Sadece sanayide veya büroda yaşanan olumsuz durum ve kazalarda değil, bir yıldan fazla süreden beri etkili olan Covid-19 salgınında olduğu gibi salgın hastalıklarda da iş sağll̆̆g ve güvenliğinin önemi daha iyi anlaşılmıştır. Dolayısılla iş sağlı̆̆l ve güvenliğiyle ilgili düzenlemelere ve faaliyetlere gereken önemin verilmesi ve önlemlerin alınmasına yönelik önemli bir katkı sağlanmıştır.

Anahtar Kelimeler: Sigorta, Sigortacılık, Işs Sağlı̆̆

Alan Tanımı: Sigortacılık

\title{
INSURANCE SECTOR'S PERSPECTIVE ON OCCUPATIONAL HEALTH AND SAFETY: A RESEARCH ON THE CITY OF ERZURUM
}

\begin{abstract}
In this study, occupational health and safety in the insurance industry is discussed. With the development of industry and economy, working conditions in many sectors have changed, and as a result, there has been an increase in adverse events and occupational accidents at workplaces. Companies in the insurance sector have taken some measures to prevent these adverse events. The most important of these measures are activities related to occupational health and safety. Thus, insurance companies try to adopt this situation by taking advantage of the concept of occupational health and safety in order to offer their employees the opportunity to work in a healthy and safe environment. The importance of occupational health and safety has been better understood not only in negative situations and accidents in the industry or in the office, but also in epidemic diseases, as in the Covid-19 epidemic, which has been effective for more than a year. Therefore, an important contribution has been made to the regulations and activities related to occupational health and safety, and to take necessary precautions.
\end{abstract}

Key Words: Occupational health and Safety, Insurance industry

JEL Code: $G 22$ 


\section{HUKUK ve İKTISSAT ARAŞTIRMALARI DERGISİ}

Cilt: 13 No: 2 Yıl: 2021 ISSN: 2146-0817 (Online)

\section{GİRIŞ}

Yaşanan gelişmeler kapsamında sigortacılık sektöründeki çalışma koşulları her geçen gün değişmektedir. Yaşanan değişimle birlikte çalışanlar, sağlik ve güvenlik açısından sorunlar yaşamakta, bu durum işletmelerin verimliliğini olumsuz biçimde etkilemektedir. İşletmeler iş sağlı̆̆ ve güvenliği (İSG) ile gerekli önlemleri alarak çalışanlarını sağlık ve güvenlik acısından korumakla kalmayıp verimliliğini de korumuş veya artırmış olacaktır. Bu doğrultuda İSG kavramı iş hayatı, çalışan, işveren ve toplum açısından büyük önem arz etmektedir.

Bu çalışmada, Erzurum ilinde faaliyet gösteren sigortacılık sektörü temsilcilerinin iş sağlığı ve güvenliğine verdiği öneme dair bir araştırma ve değerlendirme yapılmıştır.

\section{TÜRKIYYEDE İŞ SAĞLIĞI VE GÜVENLİĞİ (İSG)}

İş sağlığ ve güvenliği; iş sırasında gerçekleşebilecek, ortamdaki çevresel olumsuz durumlar sebebiyle personellerin maruz kaldıkları sağlık problemleri ve mesleki tehlikelerin ortadan kaldırılması ya da minimüma indirilmesini sağlayan bir bilim dalıdır. Bir kuruluşun yaptığı çalışmalardan etkilenen tüm insanların sağlığına ve güvenliğine etki eden nedenleri ve şartları araştıran bilim dalı olarak tanımlanmaktadır (Gündoğan, 2016: 6). İş sağlığı ve güvenliği kavramını tam anlamıyla tanımlayabilmek için bazı temel kavramların belirlenmesi ve anlaşılması gerekmektedir. 6331 sayılı Kanunun 3.maddesinde de bahsedildiği üzere bazı temel kavramların bilinmesi, tehlikelerin önlenmesinin yanı sıra, risklerin belirlenmesi, değerlendirilmesi ve bu risklerin tümden ortadan kaldırılabilmesi veya zararlarının minimuma indirilebilmesine katkı sağlamaktadır (Ceylan, 2000: 6). Türkiyede 4857 sayılı Kanunun tüm çalışanları kapsamaması nedeniyle 2012 yılında tüm çalışanların sağlığı ve güvenliğinin korunmasını kapsayan 6331 sayılı İş Sağlığı ve Güvenliği Kanunu getirilmiş böylece tüm çalışanlar koruma altına alınmıştır.

Türkiye'de iş sağlığı ve güvenliği (İSG) sistemi, günümüze kadar geliştirilmeye devam etmiş ve gereken önemini kazanmıştır. Bu sayede iş dünyasında hangi sektörde olursa olsun insan hayatına verilen önem artmış ve şirketler tarafınan benimsenmiştir. İSG kavramı sadece çalışanların sağlığını kapsamamakta, işletmenin verimli sonuçlara ulaşmasında da büyük rol oynamaktadır. Örneğin; çalışanların olumsuz bir durum yaşaması durumunda işletme, çalışanınların işgücünden ve tecrübesinden yararlanamayacak, makinaların durması nedeniyle 


\section{HUKUK ve İKTISAT ARAŞTIRMALARI DERGİSi}

Cilt: 13 No: 2 Yıl: 2021 ISSN: 2146-0817 (Online)

ise iş ve üretim kaybı yaşanacaktır. Bu nedenle Türkiye'de İSG kavramı şirketler için büyük önem arz etmektedir.

\section{SİGORTACILIK SEKTÖRÜNDE İŞ SAĞLIĞI VE GÜVENLİĞİ (İSG)}

Sigortacılık sektöründe iş kazaları bakımından olası riskler az görünse de işin niteliği gereği, azımsanmayacak kadar riskli ortamlarda bulunma zorunluluğu vardır. Önceki yıllarda riskli ortamlarda bulunma ve çalışma durmunu göz ardı eden sigortacılık sektörü, kendini geliştirdikçe zamanla bu konuya gereken önemi göstermiş, etkili kararlar almış ve alt kademelerine alınan kararları uygulama zorunluğu getirmiştir. Covid-19 salgınının kapalı ortamlarda veya yakın mesafelerde etkili olması, sigortacılık sektöründe çalışanlar için gerekli önlemlerin alınması konusunda İSG'nin öneminin daha iyi benimsenmesini sağlamıştır. Sigorta sektöründe yer alan ve yönetici durumundaki merkezler, salgın sürecinde sigorta temsilcilerini sahadan cekmiş, acente toplantılarını iptal ederek sanal ortama taşımıştır. Sigortacılık sektörü yapılan iş bakımından teknolojiyi aktif olarak kullanmak zorundadır. Sigortacılık, çalışanlarının poliçeleri düzenlemesi için bilgisayar veya mobil cihazlar üzerinden online çalışmaları, gerektiği zaman kaza ve riziko yerine gitmeleri gereken bir iş koludur.

Hem işçi sağlığı ve güvenliği açısından hem de işletmelerde istenen verimliliğin sağlanabilmesi bakımından çalışma ortamı koşullarının önemi oldukça büyüktür. $\mathrm{Bu}$ nedenle çalışma ortamı koşullarının fiziksel ve psikolojik açıdan çalışanların yaşam fonksiyonlarını tehdit etmeyen, rahatsızlık ve sıkıntıya yol açmayan, 1sı, nem, havalandırma, aydınlatma, gürültü, titreşim ve benzeri konularla ilgili sorunlardan arındırılmış olması gerekmektedir ( Beyazıt 2007: 31). Alınacak bazı güvenlik tebbirleri kücük detaylar olarak algılanabilir lakin zaman içerisinde telafisi olmayan olumsuz sonuçların önüne geçilmiş olunacaktır. Şirketlerin, çalışanlardan daha fazla verim almak için çalışma ortamını düzenlemesi ve yeni sistemler geliştirmesi hem sağlık hem de iş güvenliği bakımından önemli bir husustur. Bu yüzden iş ve çalışma ortamında bazı risk etmenlerinin yanısıra sağlanması gereken önemli bazı fiziksel imkanların varlığı kaçınılmazdır. Bahsedilmesi gereken bazı risk ve fiziksel gereklilikler; aydınlatma, ses ve gürültü, enfeksiyon riski, hasar durumunda olay yerine gitme ve araç hasarlarında sanayi kuruluşlarına giderek kaza yapan araç için durum değerlendirmesi yapmaktır.

\subsection{Aydınlatma}

İş yerlerinde işin kusursuz gerçekleştirilmesi ve çalışan kişinin göz sağlığının muhafaza edilmesi iyi bir aydınlatmayı zorunlu kılmaktadır. Bir çalışma yerinde 


\section{HUKUK ve İKTISSAT ARAŞTIRMALARI DERGISİ}

Cilt: 13 No: 2 Yıl: 2021 ISSN: 2146-0817 (Online)

her türlü görsel işlemin kusursuz yapılabilmesi ve insanın fizyolojik, psikolojik gereksinimlerinin doğru karşılanabilmesi iyi bir aydınlatma tekniğini gerektirmektedir. İyi aydınlatma, çalışılan işin üzerine yeteri kadar ş̧ık vermekten daha ileri bir anlam taşımaktadır. Gerçek amaç kolay ve uygun görme koşullarını sağlamaktır (Polat, 2006: 2). Görme koşullarının iyi sağlanması aynı zamanda çalışanların sağ 1 ğ için de önemlidir.

Çalışma ortamındaki aydınlatma personelin göz sağlı̆ğ için büyük öneme sahiptir. İş yerindeki aydınlatmanın kalitesi, çalışanların verimliliğini, sağlığını ve morallerini önemli ölçüde etkiler. İşyerindeki aydınlatma düzeyi, çalışanların davranış şekli, çalışma gücü ve görme olgularını doğrudan etkiler. Yapılan bir araştırma aydınlatmanın performans üzerinde \% 14-40 oranında etkisi olduğunu ortaya koymuştur. Görme organı olan gözün fonksiyonlarını etkileyen her türlü etken, kişilerin faaliyetlerini ve performanslarını ciddi anlamda etkilemektedir (http://www.tedavi.saglik.gov.tr). Kısaca; aydınlatma yetersizse çalışanların uyumasına veya halsizleşmesine, aydınlatma gereğinden fazlaysa çalışanların yaptıgı işe odaklanamaması, ortamda fazla durulamaması ve çalışanların sağlığ konusunda farklı olumsuz sonuçlara sebebiyet vererek iş yerinin verimliliğini de olumsuz yönde etkileyebilmektedir.

\subsection{Ses ve Gürültüi}

Gürültü ve iş kazaları arasındaki ilişkinin tespitine yönelik olarak yapılan araştırmaların sonucunda; gürültünün tepki zamanı üzerinde, hata sayısında ve üretim miktarı başına düşen hata sayısında artışa neden olduğu tespit edilmiştir. Gürültü düzeyleri ve sıklıkları en yüksek noktada iken tepki zamanının azaldığı ve hata sayısının artma eğiliminde olduğu görülmüştür. Gürültü nedeniyle, azalan tepki zamanı ve artan hata sayısı çalışanların kazaya maruz kalma oranlarında bir artışa neden olmaktadır (Yılmaz, 2007: 3). Hata sayısının fazla oluşu ise birçok sektörde olduğu gibi sigortacılıkta da önemli bir olumsuzluktur.

Sigortacılık sektöründe kullanılan sistemler ve yapılan işlemler son derece dikkat isteyen işlemlerdir. Onaylanacak poliçelerin ve bu poliçelere bireylerin istedikleri teminatları istedikleri gibi ve hatasız bir şekilde yansıtmak son derece hassas bir iştir. Ses ve gürültü, dikkati bozabileceğinden çalışanların poliçelerle ilgili yapacağı işlemlerde yanlış teminatlar vermesine yol açarak müşteri ile iletişimini olumsuz etkileyecektir. Bunun sonucunda ise çalışanın strese girmesi ve zamanla verimliliğinin düşmesi, sonrasında ise işletmenin zarara uğraması söz konusu olabilecektir. Çalışanlar açısından devamlı maruz kalındığında gelecekte kalıcı 


\section{HUKUK ve İKTISAT ARAŞTIRMALARI DERGİSi}

Cilt: 13 No: 2 Yıl: 2021 ISSN: 2146-0817 (Online)

sağl1k sorunlarına neden olabileceğinden işletmelerin ses ve gürültü hakkında ivedilikle çözüm üretmesi gerekmektedir.

\subsection{Enfeksiyon Bulaşma Riski}

Sigortacıl1k sektöründe poliçe, ruhsat, para $\mathrm{vb}$. materyaller ve ofiste ortak kullanılan kırtasiye araçları gibi malzemelere temas, enfeksiyon bulaşması bakımından en fazla risk oluşturabilecek hususlar olarak değerlendirilebilmektedir.

Covid-19 salgını ile ortak kullanilan materyaller ve malzemelere temas konusu önem kazanmış, araç-gereç, kırtasiye ve malzemelerin kullanımı bireysele dönmüş ve sosyal mesafe kuralı uygulanarak çalışanların kendilerini koruma konusuna önem verilmeye başlanmıştır. İş sağlığı ve güvenliğine verilen önemin artması ile iş yerleri dezenfenkte edilmiş, geçici olarak iş yerleri kapanmış, poliçe kesebilmek için sabit ip numaraları kaldırılmış, müşterilerle iletişim telefonla veya mail ile sağlanmış, işlemler ve poliçeler online yapılarak/düzenlenerek ilgili müşteriye dijital ortamdan ulaştırılmaya başlamıştır. Kontrollü normalleşme sürecinde ise iş yerlerinin kademeli olarak açılması ve yapılacak işlemlerin arttk iş yerlerinde yapılabilmesi için insanların tedbirli olmasını ve kurallara uymasını gerektirmektedir. Tedbirlere uyum kapsamında; iş yerlerinde müşteri veya çalışan fark etmeksizin maske kullanımı artmış, müşterilere çay ve kahve gibi ikramlar ile tokalaşma gibi uygulamalar geçici olarak kaldırılmıştır.

\subsection{Hasar Durumunda Olay Yerine Gitme}

Kazanın meydana geldiği alanda, ilk yardım yapmayı engelleyecek veya diğer kişilerin de zarar görmesine neden olabilecek malzemeler veya durumlar olabilir. Alev kaynakları, yanıcı ve yakıcı malzemeler, kesici aletler, patlama tehlikesi olan basınçlı aletler, kırık cam veya ekipman parçaları olay yerinde bulunabilecek başlıca tehlike kaynaklarıdır. Bunların ortamdan uzaklaştırılması, yeni kazalara yol açmamak açısından önemlidir. Çevre güvenliği sağlarken, iş kazası ile ilgili delil olabilecek malzeme veya bilgilerin zarar görmemesine dikkat edilmelidir. Mümkünse fotoğraf veya video çekilmeli ve malzemeler daha sonra ortamdan uzaklaştırılmalıdır. Bu sayede kazanın oluş şekli ve alınması gereken önlemler hakkında bilgi sahibi olunabilir. Ayrıca adli bir vaka oluşması durumunda delil olarak da kullanılabilir (https://www.isgnedir.com).

Meydana gelen kazalarda sigortalı bireyler bazen ne yapacaklarını bilememektedir. Bu bakımdan kaza tutanaklarını tutabilmeleri için hemen sigorta acentelerini ararlar. Sigorta acenteleri gerek müşteri memnuniyeti bakımından 


\section{HUKUK ve İKTISAT ARAŞTIRMALARI DERGİSi}

Cilt: 13 No: 2 Yıl: 2021 ISSN: 2146-0817 (Online)

gerekse sorumluluktan teknik personellerini olay yerine göndermek zorunda kalır. İnsanların kaza yerinde bilinçsizce ve meraktan dolayı toplanmaları trafiği tehlikeye atmakta, görevlilerin işini verimli olarak yapmasına engel olmaktadır. $\mathrm{Bu}$ durum teknik personellerin güvenliği için de olumsuz sonuçlara neden olabilmektedir.

\subsection{Araç Hasarlarında Sanayi Ortamına Gidip Kaza Yapan Arac İçin Durum Degerlendirmesi Yapma}

Motorlu taşıtların bakım, tamir ve servis işlemlerinin yapıldığı özel veya yetkili servislerde çok çeşitli atık ürünler açığa çıkmaktadır. İş yerinde tehlike oluşturabilecek bu ürünler; yakıt (benzin, LPG veya motorin), fren balatası, kavrama balatası, contalar, fren siviları, nemden ve dondan koruyucu maddeler, çözücüler, parçalar için temizleyiciler, cila yapıştırıcı maddeler, taşlama tozları, akü asidi, motor yağı, vites kutusu yağı, hidrolik yağı, kaynak dumanı, boyakaporta bakım ürünleri ve egzoz emisyonları olarak sayılabilir (Çetin 2011:53). İş sağlığı ve güvenliği bakımından tehlikeli olabilecek atık ürünlerin yer aldığ sanayi kuruluşlarına gidilmesi sigorta temsilcileri için bir risk faktörüdür.

Sigortacılık sektöründe teknik personel, araç servislerine araç parçaları ve yapım süreci için durum degerlendirmesi sebebi ile gitmekte ve sanayide oluşan bu atıklarla birebir karşı karşıya gelebilmektedir. Sadece bu atıklar degil, araçların tamirinde kullanılan lift gibi araç ve gereçler çok büyük tehlike arz etmektedir. Bu gibi aletler kazaya yol açabileceği gibi telafisi olmayan sakatlıklara da neden olabilmektedir.

\section{ARAŞTIRMANIN AMACI, YÖNTEMI VE BULGULAR}

Araştırmanın amacı sigortacılık sektöründeki acentelerin faaliyette bulundukları işlerden dolayı yaşadıkları iş sağlığı tehlikelerin belirlenmesidir. Anketimiz Erzurum merkezde bulunan bazı sigorta acenteleri ve acentede çalışanlar ile yapılmıştır. İlk dört soru ankete katılan kişilerin cinsiyetlerini, yaşlarını, eğitim düzeylerini ve sigorta sektöründe hangi pozisyonda çalıştıklarına yöneliktir. Diğer sorular ise sektördeki iş sağlığı ve güvenliği ile ilgili bilgi düzey ve tutum ile görüşleri içermekte olup, ankette beşli likert yöntemi kullanılmış ve istatistiksel değerlendirmede ise SPSS kullanılmıştır. 


\section{Tablo 1. Demografik Veriler}

\begin{tabular}{|l|l|}
\hline Cinsiyetiniz & (25 kişi) Bayan (55 kişi ) Erkek \\
\hline Yaş aralığınız & (42 kişi) 18-29 (27 kişi) 30-45 (11 \\
& kişi) 46 ve üstü \\
\hline Eğitim Düzeyiniz & (15 kişi) Lise (39 kişi) Ön lisans \\
& $\begin{array}{l}\text { (20 kişi) Lisans (6 kişi)Yüksek } \\
\text { lisans }\end{array}$ \\
\hline $\begin{array}{l}\text { Sigortacılık Sektöründe çalışma } \\
\text { pozisyonunuz }\end{array}$ & $\begin{array}{l}\text { (52 kişi ) teknik personel } \\
\text { (28 kişi) büro personeli }\end{array}$ \\
\hline
\end{tabular}

Ankete 80 kişi katılmış, katılanların cinsiyet dağılımları; bayan 25 kişi (\% 31,25), erkek 55 kişi $(\%$ 68,75) olarak tespit edilmiştir. Ankete katılanların yaşlarının dağılımı; 18-29 arası 42 kişi (\% 52,50), 30-45 arası 27 kişi (\% 33,75), 46 ve üstü 11 kişi (\% 13,75)'dir. Eğitim düzeyi dağılımı; Lise 15 kişi $(\% 18,75)$, önlisans 39 kişi $(\% 48,75)$, lisans 20 kişi $(\% 25,00)$ ve yükseklisans 6 kişi $(\% 7,50)$ olarak belirlenmiştir. Ayrıca sigortacılık sektöründeki çalışma pozisyonunun dağılımı; teknik çalışan olan kişi sayısı 52 kişi $(\% 65,00)$, büro personeli olan kişi sayısı 28 (\% 35,00)'dir.

Çalışanların İSG hakkındaki bilgi düzeyi ve tutumlarını yansıtan görüşlerin dağılımı Tablo 2.'de yer almaktadır. 


\section{Tablo 2. Sigortacılık Sektörü Çalışanlarının İSG ye Bakış Açısı}

\begin{tabular}{|c|c|c|c|c|c|c|}
\hline & & 焉 & E & 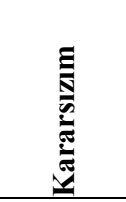 & E & 尊 \\
\hline 1 & $\begin{array}{l}\text { Bürodaki } 4 \text { aydınlatmalar } \\
\text { bilgisayar, laptop ve telefon gibi } \\
\text { elektronik cihazlar göz sağlığımızı } \\
\text { bozar. }\end{array}$ & $\% 0$ & $\% 0$ & $\% 2,50$ & $\% 18,75$ & $\% 78,75$ \\
\hline 2 & $\begin{array}{l}\text { Çalışma ortamımızdaki ses ve } \\
\text { gürülttü sağlığınızı bozmaktadır? }\end{array}$ & $\% 0$ & $\% 0$ & $\% 7,50$ & $\% 31,25$ & $\% 61,25$ \\
\hline 3 & $\begin{array}{l}\text { Bilgisayar karşısında geçirilen zaman } \\
\text { diliminde duruş bozukluğu gibi } \\
\text { fizyolojik sorunlar yaşanmaktadır. }\end{array}$ & $\% 0$ & $\% 0$ & $\% 0$ & $\% 15,00$ & $\% 85,00$ \\
\hline 4 & $\begin{array}{l}\text { Ofise gelen müşterilerle tokalaşma } \\
\text { veya temas kurulması sağlığınızı } \\
\text { etkilemektedir. }\end{array}$ & $\% 0$ & $\% 15,00$ & $\% 10,00$ & $\% 12,50$ & $\% 62,50$ \\
\hline 5 & $\begin{array}{l}\text { Müşterilerle sürekli ve uzun süreli } \\
\text { telefon görüşmeleri duyma ve baş } \\
\text { ağrısı gibi problemlerine yol } \\
\text { açmaktadır. }\end{array}$ & $\% 0$ & $\% 0$ & $\% 6,25$ & $\% 28,75$ & $\% 65,00$ \\
\hline 6 & $\begin{array}{l}\text { Bilgisayar ortamında yaşanan sanal } \\
\text { görüşmelerden ve çeşitli evrak } \\
\text { çalışmalarından dolayı zihin } \\
\text { deformasyonu yaşanmaktadır. }\end{array}$ & $\% 0$ & $\% 8,75$ & $\% 5,00$ & $\% 36,25$ & $\% 50,00$ \\
\hline 7 & $\begin{array}{l}\text { Müşteriler tarafından kaza yerine } \\
\text { çağırılmak çalışan personeli yaşanan } \\
\text { aksilikten doğacak herhangi bir } \\
\text { olumsuzluğa karşı riske atmaktadır. }\end{array}$ & $\% 0$ & $\% 3,75$ & $\% 5,00$ & $\% 33,75$ & $\% 57,50$ \\
\hline 8 & $\begin{array}{l}\text { Araç servislerindeki hasar takibi } \\
\text { hususunda, araç yapım süresince } \\
\text { sanayi ortamında bulunulması } \\
\text { çalışan açısından tehlike arz } \\
\text { etmektedir. }\end{array}$ & $\% 10,00$ & $\% 11,25$ & $\% 13,75$ & $\% 43,75$ & $\% 21,25$ \\
\hline 9 & $\begin{array}{l}\text { İşs sağlığı ve güvenliği çalışma } \\
\text { süresince ortaya çıkacak sorun veya } \\
\text { tehlikeleri minimum seviyeye indirir. }\end{array}$ & $\% 0$ & $\% 0$ & $\% 0$ & $\% 13,75$ & $\% 86,25$ \\
\hline 10 & $\begin{array}{l}\text { İs sağlığı güvenliğinin ortaya } \\
\text { çıardığı disiplinli çalışmalar, bireyin } \\
\text { bulunduğu ortama daha olumlu } \\
\text { etkiler sağlar. }\end{array}$ & $\% 0$ & $\% 0$ & $\% 0$ & $\% 10$ & $\% 90,00$ \\
\hline
\end{tabular}




\section{Tablo 3. Verilerin İstatistiksel Dağılımı}

\begin{tabular}{|c|c|c|c|c|c|c|c|c|c|c|}
\hline \multirow[t]{2}{*}{ No } & \multicolumn{2}{|c|}{$\begin{array}{l}\text { Kes. } \\
\text { Katılmiyorum }\end{array}$} & \multicolumn{2}{|c|}{ Katılmıyorum } & \multicolumn{2}{|c|}{ Kararsızım } & \multicolumn{2}{|c|}{ Katılıyorum } & \multicolumn{2}{|c|}{$\begin{array}{l}\text { Kes. } \\
\text { Katılıyorum }\end{array}$} \\
\hline & f & $\%$ & f & $\%$ & $\mathbf{f}$ & $\%$ & $\mathbf{f}$ & $\%$ & $\mathbf{f}$ & $\%$ \\
\hline $\begin{array}{l}1 . \\
\text { soru }\end{array}$ & 0 & 0 & 0 & 0 & 2 & 2,50 & 15 & 18,75 & 63 & 78,75 \\
\hline $\begin{array}{l}2 . \\
\text { soru }\end{array}$ & 0 & 0 & 0 & 0 & 6 & 7,50 & 25 & 31,25 & 49 & 61,25 \\
\hline $\begin{array}{l}3 . \\
\text { soru }\end{array}$ & 0 & 0 & 0 & 0 & 0 & 0 & 12 & 15,00 & 68 & 85,00 \\
\hline $\begin{array}{l}4 . \\
\text { soru }\end{array}$ & 0 & 0 & 12 & 15,00 & 8 & 10,00 & 10 & 12,50 & 50 & 62,50 \\
\hline $\begin{array}{l}5 . \\
\text { soru }\end{array}$ & 0 & 0 & 0 & 0 & 5 & 6,25 & 23 & 28,75 & 52 & 65,00 \\
\hline $\begin{array}{l}6 . \\
\text { soru }\end{array}$ & 0 & 0 & 7 & 8,75 & 4 & 5,00 & 29 & 36,25 & 40 & 50,00 \\
\hline $\begin{array}{l}7 . \\
\text { soru }\end{array}$ & 0 & 0 & 3 & 3,75 & 4 & 5,00 & 27 & 33,75 & 46 & 57,50 \\
\hline $\begin{array}{l}8 . \\
\text { soru }\end{array}$ & 8 & 10,00 & 9 & 11,25 & 11 & 13,75 & 35 & 43,75 & 17 & 21,25 \\
\hline $\begin{array}{l}9 . \\
\text { soru }\end{array}$ & 0 & 0 & 0 & 0 & 0 & 0 & 11 & 13,75 & 69 & 86,25 \\
\hline $\begin{array}{l}10 . \\
\text { soru }\end{array}$ & 0 & 0 & 0 & 0 & 0 & 0 & 8 & 10,00 & 72 & 90,00 \\
\hline
\end{tabular}

Ankete katılanların \% 78,75'i, bürodaki aydınlatmalar, bilgisayar, laptop ve telefon gibi elektronik cihazların göz sağlığını olumsuz etkilediği görüşüne kesinlikle katıldıklarını bildirmişlerdir. Çalışma ortamındaki ses ve gürültünün çalışanların sağlığını bozuyor düşüncesine katılanların oranı \% 61,25'dir. Bilgisayar karşısında geçirilen zaman diliminde duruş bozukluğu gibi fizyolojik sorunlar yaşayanların oranı \% 85'dir. Müşterilerle sürekli ve uzun süreli telefon görüşmeleri, duyma ve başağrısı gibi problemlere yol açmaktadır görüşünün oranı $\%$ 65'tir. Bilgisayar ortamında yaşanan sanal görüşmeler ve çeşitli evrak çalışmalarından dolayı zihin deformasyonu yaşanmaktadır görüşüne katılanların oranı \% 50'dir. Müşteriler tarafından kaza yerine çağrılmanın çalışanı yaşanan aksilikten doğacak herhangi bir olumsuzluğa karş1 riske atmaktadır görüşüne katılanların oranı \%57,50' dir. Araç servisindeki hasar takibi hususunda, aracın tamir bakım süresince sanayi ortamında bulunulması, çalışan açısından tehlike arz etmektedir düşüncesine katılanların oranı \% 43,75'dir. İş sağlı̆̆1 ve güvenirliği çalışma süresince ortaya c1kacak sorun veya tehlikeleri minimum seviyeye indirir görüşüne katılanların oranı \% 86,25’tir. İş sağlığı ve güvenliğinin ortaya çıkardığ 
disiplinli çalışmalar, bireyin bulunduğu ortama daha olumlu etkiler sağlar görüşünün oranı ise $\% 90$ olarak tespit edilmiştir.

\section{Faktör Analizi}

\begin{tabular}{|l|l|r|}
\hline \hline KMO and Bartlett's Test \\
\hline Kaiser-Meyer-Olkin Measure of Sampling Adequacy. &, 852 \\
\hline \multirow{3}{*}{ Bartlett's Test of Sphericity } & Approx. Chi-Square & 3344,554 \\
\cline { 2 - 4 } & df & 178 \\
\cline { 2 - 3 } & Sig. &, 000 \\
\hline
\end{tabular}

\begin{tabular}{|l|r|r|}
\hline \multicolumn{3}{|c|}{ Communalities } \\
\hline bir & Initial & Extraction \\
\hline iki & 1,000 &, 803 \\
\hline üç & 1,000 &, 859 \\
\hline dört & 1,000 &, 862 \\
\hline beş & 1,000 &, 784 \\
\hline alt1 & 1,000 &, 887 \\
\hline yedi & 1,000 &, 859 \\
\hline sekiz & 1,000 &, 891 \\
\hline dokuz & 1,000 &, 909 \\
\hline on & 1,000 &, 913 \\
\hline
\end{tabular}

\section{V.SONUÇ}

Günümüzde çağa ayak uyduran sigortacılık sektörü, teknolojinin gelişmesine paralel olarak gelişimini hızlandırmıştır. Bu gelişimle birlikte büroların düzen şekli degişmiş, çalışanların konfor düzeyi yükselmiş, büroda kullanılan malzemeler degişime uğramıştır. Bu gelişimlerin amacı öncelikle çalışanlardan yüksek verim almaktır. Bu amaç doğrultusunda, iş bölümü yapılarak çalışanlara İSG bakımından güvenilir ve sağlıklı bir çalışma ortamı temin etmek ve böylece iş kazalarını en az düzeye indirmek mümkün olabilecektir.

İSG eğitiminin, İSG kültürüne etkisini araştıran bir çalışmada, İSG eğitimlerinin çalışanlara bir güvenlik kültürü kazandırmasının yanı sıra işletmelere rekabet avantaj1 sağladığ1 öne sürülmektedir. Aynı çalışmada; kişilerde ve toplumda güvenlik kültürünün yerleşebilmesi için İSG eğitimleri üzerinde önemle durulmalı, sağlık ve güvenlik bilinci, toplumun tamamına küçük yaştan itibaren aşılanmalı, eğitimler sadece bir prosedür olarak algılanmamalıdır sonucu ortaya 


\section{HUKUK ve İKTISAT ARAŞTIRMALARI DERGİSi}

Cilt: 13 No: 2 Yıl: 2021 ISSN: 2146-0817 (Online)

konmuştur. Bu noktada, eğitim için yeteri kadar emek, zaman ve kaynak harcamaktan kaçınılmamalıdır (Aktay, 2014: 146).

Örnek olarak; Covid-19 salgınına yönelik alınan tedbirler İSG kapsamında sigortacılık sektöründe de kapsama alınmıştır. İşletmeler personellerini korumak için iş yerlerini dezenfekte etmiş, maske kullanımını zorunlu hale getirmiş, sıralı çalışma mesaisi uygulamış, birebir görüşmeyi azaltarak personelini korumaya çalışmıştır. İSG kapsamında alınan bu tedbirler yetersiz kaldığından şirketler sigortacılığın dijital yönünü daha aktif kullanmış, müşterileri iş yerlerine davet etmeden bir telefon ile işlemleri tamamlama yoluna başvurmuştur.

Alınacak en ufak bir tedbir bile olası bir kazanın önüne geçebilir. Hangi sektör olursa olsun İSG kurallarının benimsetilmesinin, çalışanlar için olduğu kadar aileler ve toplum için de son derece önemli olduğu unutulmamalıdır.

Ek olarak sunulabilecek öneriler aşağıdaki gibi sıralanabilir:

- Covid-19 salgınına karşı alınacak tedbirlerden en önemlisi, iş yerinde kullanılan ortak metaryellerin kaldırılması ve gerekirse bütün çalışanlara çalışma masası temin edilerek özellikle bilgisayar gibi ofis malzemelerinin kendilerine ait olması gerekmektedir.

- Hasarın meydana geldiği olay yerine gidildikten sonra iş güvenliği sağlanmadan hiçbir şekilde olaya müdahale edilmemesi gerekmektedir.

- Sanayi gibi yerlerde hasar tespiti yapılırken iş güvenliği sağlandıktan sonar, servis sorumlusu rehberliğinde işlem yapılması ve sonuçlandırılmasına dikkat edilmelidir.

- Sigorta sektörü temsilcilerinin ve çalışanlarının iş güvenliği ve sağlı̆̆ konusunda önemli adımların atılması ve düzenli eğitimlerin verilmesi gerekmektedir.

\section{Kaynakça}


İstanbul Üniversitesi Sosyal Bilimler Enstitüsü, Çalışma Ekonomisi ve Endüstri İlişkileri Anabilim Dalı, Yüksek Lisans Tezi, İstanbul (2014).

Ceylan Hüseyin. "Imalat Sistemlerindeki İş Kazalarının Tahmini İçin A ̆̆ırlıklandırılmış Ortalamalardan Sapma Tekniği’', Gazi Üniversitesi, Fen Bilimleri Enstitüsü, Yayınlanmamış Doktora Tezi, Ankara (2000). 


\section{HUKUK ve İKTISAT ARAŞTIRMALARI DERGİSI}

Cilt: 13 No: 2 Yıl: 2021 ISSN: 2146-0817 (Online)

Çevre Sağlığını Etkileyen Etmenler (2006). www.tedavi.saglik.gov.tr

Çetin Mehmet. "Oto bakım ve onarım servislerinde atıklar ve çevre kirleticiler', Tarım Bilimleri Araştırma Dergisi (2011; 4:53).

Gündoğan Bahadır. "Mesleki Ve Teknik Anadolu Liselerinin Motorlu Araçlar Teknolojisi Bölümü Otomotiv Elektromekanik Teknolojisi Atölyesi İş ve İşlem Basamaklarının $\dot{I}_{S ̧}$ Sağllğg ve Güvenliği Yönünden İncelenmesi ve Programlanmasl', Gebze Üniversitesi Sosyal Bilimler Enstitüsü, Yüksek Lisans Tezi, İstanbul (2016).

Hayta Bayazıt A. "Çalışma ortamı koşullarının işletme verimliliği üzerine etkisi", Ticaret ve Turizm Eğitim Fakültesi Dergisi, ( 2007; 32).

Kaza Anında Yapılması Gerekenler Nelerdir https://www.isgnedir.com/

Polat İhsan. "İsyeri Ergonomisinin örgütsel stres üzerine etkisi: Erzurum ilindeki Banka Çalışanları Üzerinde Bir Uygulama", Yüksek Lisans Tezi, Atatürk Üniversitesi Sosyal Bilimleri Enstitüsü, Erzurum (2006).

Yılmaz Gürbüz, “iş Kazalarının Nedenleri", http://www.isguvenligi.net / (2007). 